\title{
A Multiple Criteria Risk Analysis Model and a Case Study in Metal Industry
}

\author{
Safinaz Esra Ciftci' ${ }^{1}$, Feyzan Arikan² \\ ${ }^{1}$ Occupational Health and Safety Directorate, The Ministry of Family, Labor and Social Services, Ankara, Turkey \\ ${ }^{2}$ Industrial Engineering Department, Gazi University, Ankara, Turkey \\ Email: farikan@gazi.edu.tr
}

How to cite this paper: Ciftci, S. E., \& Arikan, F. (2020). A Multiple Criteria Risk Analysis Model and a Case Study in Metal Industry. Open Journal of Business and Management, 8, 2048-2070.

https://doi.org/10.4236/ojbm.2020.85125

Received: July 17, 2020

Accepted: August 30, 2020

Published: September 2, 2020

Copyright $\odot 2020$ by author(s) and Scientific Research Publishing Inc. This work is licensed under the Creative Commons Attribution International License (CC BY 4.0).

http://creativecommons.org/licenses/by/4.0/ (c) (i) Open Access

\begin{abstract}
Healthy workers and appropriate working conditions not only ensure enhancing the quality of life of individuals but also contribute to productivity of workplaces. To reach these benefits, occupational health and safety (OHS) risk management is the key concept for all kinds of organizations. In this study, a multiple criteria risk analysis model is proposed and applied in a workplace operating in the metal industry. The model integrates the Decision Making Trial and Evaluation Laboratory Technique (DEMATEL), the Analytical Network Process (ANP) and the Technique for Order of Preference by Similarity to Ideal Solution (TOPSIS). The model provides a scientific approach for risk assessment and suggests a precedence order of the workshops for the risk control stage. The study contributes to the literature by considering the interrelations between risk factors and determining a ranking order in order to put preponderant risks forward with an integrated approach. Furthermore, in the application study, it is considered not only the traditional risk factors but also the psycho-social factors. The findings of the study offer fruitful inspirations to the managers in metal industry and the approach is believed to have a wide range of applications for risk assessment and analysis in the field of OHS.
\end{abstract}

\section{Keywords}

Occupational Hazards, Risk Management, Multi-Criteria Decision Making

\section{Introduction}

The occupational health and safety (OHS) risk management has gained increasing significance to ensure the continuity of production and to increase the business efficiency. The phases of the OHS risk management constitutes mainly 
risk assessment and risk treatment. Risk assessment is composed of risk analysis and risk evaluation steps (Aven, 2011). Risk analysis traditionally concentrates on risk/hazard identification, evaluation and hierarchisation in order to put preponderant risks forward.

The building blocks of the risk assessment and management have been constructed since 1970s and 1980s as a scientific field (Aven, 2016). In this duration the OHS risk management has become common by a variety of standards and guidelines. According to the European Union (EU) regulations (Council Directive 89/391/EEC) each member state of the EU has to establish national legislation to demand risk assessment procedures in enterprises of all sizes (EEC, 1989). OHS risk management interventions that are either mandatory arising from government legislation or voluntary arising through private organizations, have been giving promising results on employee health and safety and associated economic outcomes (Robson et al., 2007).

The efficient implementation of an OHS risk management highly depends on assessing risks adequately (Silva \& Amaral, 2019). Difficulties on measuring industrial risks required the development of alternative methods. The traditional risk assessment activities that are based mainly on the estimation of the probability of occurrence of a certain event and the severity of its consequences do not consider the interdependence of indicators and knowledge of the people having different types of competences who are participating in the risk analysis. To reach the valid risk assessment by handling these critics, the current study proposed a multiple criteria risk analysis model and presented its application in a workplace operating in the metal industry. The model integrates DEMATEL-ANP-TOPSIS techniques for risk analysis. The DEMATEL method is utilized to identify interrelationships between risk factors and convert them into the network structure that is the input for ANP. ANP is performed to compute relative weights of risk factors, which is risk assessment. The next step is the risk control stage. TOPSIS comes handy to find the precedence order of the workshops in the workplace based on the relative importance of risk factors. The proposed integrated approach is utilized for the risk analysis in a metal industry company.

The remainder of the paper is organized as follows: In section 2, the literature on OHS risk analysis is reviewed in detail to highlight the contribution of this study. Section 3 introduces the existing methods. Section 4 is devoted to the proposed multiple criteria risk analysis model. Application study is presented in section 5. Section 6 presents the obtained results and discussion. Final section summarized conclusions and future directions.

In the literature terminological differences exist: The term "risk analysis" is utilized over the term "risk assessment" or "safety analysis" that appears to be more common (Harms-Ringdahl, 2001). Throughout of this paper risk and hazard terms are used interchangeable. Although criteria and attribute terms are used interchangeable in the literature, throughout this study the term criteria are preferred and represent the risk factors. 


\section{Literature Review}

There are numerous researches on OHS risk management in the literature. The literature addressing risk assessment can be classified into two groups of studies that 1) review and/or propose risk analysis methodologies, 2) concentrate on risk analysis and assessment applications:

When the first group of studies (see e.g. in Aven, 2010; 2011; 2016) is investigated, it is observed that the historical evolvement of risk analysis methodologies started with the statistical data and analysis on occupational accidents. Jacinto and Aspinwall (2004) mentioned in their survey study for reporting occupational accidents in the EU countries that the statistical data and analysis are commonly accepted tool. Although legislative action and statistical data are essential to promoting better working conditions, some other instruments are also required to monitor progress and to make sure that objectives have been attained (Silvestri et al., 2012). Therefore several techniques have been developed for risk analysis including Hazard and Operability Study (HAZOP), Failure Modes, Effects, and Criticality Analysis (FMECA), Fault Tree Analysis (FTA), Event Tree Analysis (ETA), Cause Consequence Analysis (CCA) (ECAST 2009, Health and Safety Laboratory, 2000). Tixier et al. (2002) reviewed 62 risk analysis methodologies and mentioned their limitations and application fields. They also suggested that there is not only one general method to deal with the problematic of industrial risks. The type of the industrial sector and the problem specific requirements shape the needs in the risk assessment methodology. Difficulties on measuring risks required the development of alternative methods (Fargnoli et al., 2019). Evenly, in regulatory documents although there is no specific requirement concerning quality control of risk analysis (Goerlandt et al., 2017), several authors have commented on the validity and validation in quantitative risk analysis (Aven \& Heide, 2009; Goerlandt et al., 2017; Pasman et al., 2009; Rae et al., 2014; Rosqvist, 2010; Metzler et al., 2019).

In recent years, Multiple Criteria Decision Making (MCDM) methods have been utilized to help decision-makers in prioritizing the risks and come handy for the needs of alternative risk analysis methods. Knowledge of the people having different types of competences who are participating in the risk analysis is quite important (Tixier et al., 2002). Because MCDM methods heavily include human participation and judgments (Kubler et al. 2016), they serve to reach the valid risk assessment by representing and integrating expert knowledge in a scientific way that is the inspritation of the current study. In the literature there are several studies (e.g. Dabbagh \& Yousefi, 2019; Samantra et al., 2017; Ilangkumaran et al., 2015; Mahdevari et al., 2014; Aminbakhsh et al., 2013; Silvestri et al., 2012) on OHS risk analysis by MCDM approaches. A recent critical state-of-the-art review of OHS risk assessment studies using MCDM-based approaches can be found in Gul's (2018) study.

Among the MCDM methods, DEMATEL and ANP are utilized in an integrated way by Tzeng et al. (2007) in the literature for the first time in the evalua- 
tion of intertwined effects in e-learning programs. In the area of risk assessment, the DEMATEL-ANP integrated approach is utilized by Fazli et al. (2015) in crude oil supply chains and by Dehdasht et al. (2017) in oil and gas construction projects. Hatefi and Tamosaitiene (2019) utilized fuzzy versions of both methods in integrated way and analyzed risks in construction projects. However, the risk factors in supply chains and in construction projects are totally different from that of in metal industry that is the concentration point of the current study.

When the second group of studies (2) which concentrate on risk analysis and assessment applications are investigated, it is observed that only few of them have dealt with the practical needs of the companies in metal industry and implementing risk assessment: Welch et al (2007) presented an updated analysis for the change in prevalence of radiographic abnormalities and asbestos-related disease among 18,211 sheet metal workers examined between 1986 and 2004. The results of their study suggest that the efforts to reduce asbestos exposure in the 1980s through strengthened OHS Administration regulation have had a positive public health impact. Andersen et al. (2007) investigated owner attitudes and self-reported behavior towards modified work after injury-absence in small enterprises by conducting a survey study with twenty-two owners of small construction and metal-processing enterprises. Hasle et al. (2009) interviewed owners of 22 small (1 - 19 employees) construction and metal industry enterprises and concluded that there is a need for educating owners and workers about multiple contributing accident factors and attribution bias. Rajala and Vayrynen (2010) examined recorded occupational accidents in mechanical engineering and metal production companies in Finland. They mentioned that the outputs guide companies towards safer working. Kines et al. (2013) proposed an integrated approach to safety management by combining behavior-based and culture change approaches. The approach was demonstrated in small (10-19 employees) metal industry enterprises and instructions and forms for the activities are given as a safety tool box. Laitinen et al. (2013) investigated the validity of the Elmeri+ observation method in predicting the accident risk of a workplace. Their study material consisted of 128 companies within the mechanical engineering, the metal industry and the electronics industry. Reinhold and Pallon (2014) presented a survey study in Latia. They selected voluntary participants from 10 enterprises in metal industry as 95 male workers. The results of the conducted questionnaire showed that noise and chemicals exceeded the occupational exposure limits. Yilmaz and Senol (2017) ordered risk factors by fuzzy TOPSIS in a metal industry company.

In the aforementioned studies the only study performed risk analysis in metal industry by MCDM belongs to Yilmaz and Senol (2017). However they did not consider the interrelations between risk factors and psycho-social working conditions. Rests of the studies are mainly survey studies and their scientific approaches are statistical evaluations.

The current study proposes a multiple criteria risk analysis model by the inte- 
gration of DEMATEL-ANP-TOPSIS. It contributes the literature by the fact that the model provides a scientific guide for risk assessment and its contribution goes further by suggesting a precedence order of workshops in the workplace to be utilized during the risk control stage. The current study also considers not only the traditional risk factors but also the psychosocial risk factors, and their interrelations in a metal industry plant.

\section{Methods}

\subsection{DEMATEL (The Decision Making Trial and Evaluation Laboratory Technique)}

DEMATEL method, developed by the Science and Human Affairs Program of the Battelle Memorial Institute of Geneva between 1972 and 1976, was used for researching and solving the complicated and intertwined problems (Tzeng \& Huang, 2011). The method was created based on expert knowledge to analyze factors that affect the system and expose both strength and influence among the factors in addition to solve the cause-and-effect relationship between factors (Dehdasht et al., 2017). The analysis is based on matrix calculations. In step 1, the direct-relation matrix " $A=\left[a_{i j}\right]$ ", is constructed by asking the influential degree of the criterion $i$ to the criterion $j\left(a_{i j}, i, j=1,2, \cdots, n\right)$ on a $0-4$ scale in which 0 (no influence), 1 (low influence), 2 (medium influence), 3 (high influence), and 4 (very high influence) by utilizing pairwise comparison of criteria. If there are multiple experts then the arithmetic mean of their response for each influence is recorded in the direct relation matrix. Then, the normalized direct relation matrix " $M$ " is obtained through Equation (1).

$$
M=\min \left(\left(\frac{1}{\max _{i} \sum_{i=1}^{n}\left|a_{i j}\right|} \frac{1}{\max _{j} \sum_{j=1}^{n}\left|a_{i j}\right|}\right)\right) \cdot A
$$

where $i, j=1,2, \cdots, n$.

In step 2 , the total relation matrix “ $T=\left[t_{i j}\right]$ ” that represents the sum of direct and indirect influences between the criteria relations is attained by the following Equation (2):

$$
T=\sum_{k=1}^{\infty} M^{k}=M(I-M)^{-1}
$$

where $i$ is the identity matrix.

In step 3, the sum of rows and the sum of columns of the total relation matrix $T=\left[t_{i j}\right]$, for $i, j=1,2, \cdots, n$; are calculated and denoted as vector $R$ and $C$ respectively. They are obtained by formulas in Equations (3) and (4). The vector $(R+C)$ called "prominence" is calculated by adding $R$ to $C$. The total relation strength of a criterion is represented by the value of $r_{i}+c_{j}, \forall i=j$. The vector $(R-C)$ called "relation" is obtained by subtracting $R$ from $C$, which divides criteria into a cause group and an effect group. A criterion is classified as a net cause (sender) if the value of $r_{i}-c_{j}, \forall i=j$, is positive, and it is classified as a net effect (receiver) if it is negative. 


$$
\begin{aligned}
& R=\left[\sum_{j=1}^{n} t_{i j}\right]_{n \times 1}=\left[t_{i}\right]_{n \times 1} \\
& C=\left[\sum_{i=1}^{n} t_{i j}\right]_{1 \times n}=\left[t_{. j}\right]_{1 \times n}
\end{aligned}
$$

In step 4, the causal diagram can be acquired by mapping the all dataset of the prominence and relation vectors where the horizontal axis is $R+C$ and the vertical axis is $R-C$. A structural model called Network Relation Map (NRM) is built by considering influences that are greater than a threshold value (alpha) defined by the decision analyst based on expert opinions to visualize the complex correlation. The main purpose of choosing a threshold value is to be filtered out the negligible relationships from the total relation matrix $\mathrm{T}$. Therefore, NRM presents valuable insight for making decisions.

\subsection{ANP (The Analytical Network Process)}

ANP is a generalization of the Analytic Hierarchy Process (AHP) developed by Thomas L. Saaty in 1965 (Saaty, 2004; Saaty \& Vargas, 2006). ANP computes the relationships between decision elements (a goal, criteria, sub-criteria, and alternatives) with a network structure in which, feedback and interconnection are possible between clusters.ANP can be summarized in four steps: In step 1, the decision problem is defined and converted into a network structure, where all decision elements can communicate with each other. In step 2, similar to pairwise comparison performed in AHP, decision elements in each cluster are compared pairwise. Clusters themselves are also compared based on their role and effect on achieving goals as well as interdependencies between criteria of each cluster. The effect of criteria on each other can be provided through the eigenvector. The Saaty scale utilized in the decision making process ranges from 1 to 9: 1 for equal importance; 3 for moderate importance; 5 for strong importance; 7 for very strong importance; 9 for extreme importance; and 2, 4, 6, 8 for respective compromises. When $A$ is the pairwise comparison matrix of the criteria, $w$ is the eigenvector and $\lambda_{\max }$ is the largest eigenvalue, the internal importance vector which represents the relative importance of elements or clusters, is obtained by Equation (5). Geometric mean approximation is usually used to calculate the eigenvector $w$.

$$
A w=\lambda_{\max } w
$$

ANP allows for the consistency of the decision makers to be assessed to determine their accuracy in the overall decision making exercise. To test the consistency of the eigenvector of the comparison matrix of the criteria, Saaty defined the consistency ratio $(C R)$ as the consistency index $(C D) /$ random index (RI). $C I$ is defined as $\left(\lambda_{\max }-n\right) /(n-1)$, where $\lambda_{\max }$ is the largest eigenvalue of the considered matrix of order $n$. The $R I$ is calculated by simulation studies according to the number of criteria. The recommended consistency ratio is less than or equal to 0.1 . In step 3, a super-matrix is generated and it is converted to 
a weighted super-matrix. In step 4, the best option is selected by utilizing the limited super-matrix that is obtained from the weighted super-matrix.

\subsection{TOPSIS (The Technique for Order of Preference by Similarity to Ideal Solution)}

TOPSIS, developed by Hwang and Yoon (1981), is based on the idea that the chosen alternative should have the shortest Euclidean distance from the ideal solution and the farthest distance from the negative-ideal solution for solving multiple attribute decision making problems. The steps of the technique based on (Hwang \& Yoon, 1981; Shih et al., 2007) are as follows:

Step 1. Construct the decision matrix $D$. $A_{k}$, represents $n$ alternatives for $k=1,2, \cdots, n ; x_{j}$ denotes $m$ criteria for $j=1,2, \cdots, m$. The decision matrix is defined as $D=\left[x_{k j}\right]$ where $x_{k j}$ is the outcome of the $k^{\text {th. }}$ alternative for the $f^{\text {th }}$ criterion.

Step 2. Construct the normalized decision matrix $R$ where $R=\left[r_{k j}\right] ; r_{k j}$ is calculated by vector normalization for $k=1,2, \cdots, n$ and $j=1,2, \cdots, m$.

$$
r_{k j}=\frac{x_{k j}}{\sqrt{\sum_{k=1}^{n} x_{k j}^{2}}}, k=1,2, \cdots, n ; j=1,2, \cdots, m
$$

Step 3. Calculate the weighted normalized decision matrix. The weight vector for the criteria is $w$, where $w=\left\{w_{j}, j=1,2, \cdots, m\right\}$ and $\sum_{j} w_{j}=1$. The weighted normalized value $v_{k j}$ is calculated as follows:

$$
v_{k j}=w_{j} r_{k j}, k=1,2, \cdots, n ; j=1,2, \cdots, m
$$

Step 4. Determine the ideal $\left(A^{+}\right)$and negative ideal $\left(A^{-}\right)$solutions. These solutions are calculated by using Equations (8)-(9) where $J_{1}$ is associated with the benefit (maximization) criteria and $J_{2}$ is associated with the cost (minimization) criteria.

$$
\begin{aligned}
& A^{+}=\left\{\left(\max _{x} v_{k j} \mid j \in J_{1}\right),\left(\min _{k} v_{k j} \mid j \in J_{2}\right) \mid k=1,2, \cdots, n\right\}=\left\{v_{1}^{+}, v_{2}^{+}, \cdots, v_{m}^{+}\right\} \\
& A^{-}=\left\{\left(\min _{k} v_{k j} \mid j \in J_{1}\right),\left(\max _{k} v_{k j} \mid j \in J_{2}\right) \mid k=1,2, \cdots, n\right\}=\left\{v_{1}^{-}, v_{2}^{-}, \cdots, v_{m}^{-}\right\}
\end{aligned}
$$

Step 5. Calculate the separation measures $\left(S_{k}^{+}, S_{k}^{-}\right)$. Originally, TOPSIS utilized Euclidean distance to measure separations. The separations from the ideal solution and from the negative-ideal solution are calculated by Equations (10) and (11) respectively.

$$
\begin{aligned}
& S_{k}^{+}=\sqrt{\sum_{j=1}^{m}\left(v_{k j}-v_{j}^{+}\right)^{2}}, k=1,2, \cdots, n \\
& S_{k}^{-}=\sqrt{\sum_{j=1}^{m}\left(v_{k j}-v_{j}^{-}\right)^{2}}, k=1,2, \cdots, n
\end{aligned}
$$

Step 6. Calculate the relative closeness to the ideal solution $\left(C_{k}^{+}\right)$and Rank the preference order. If $C_{k}^{+}=1$ then the alternative $k$ is close to the ideal solution; if $C_{k}^{+}=0$, then alternative $k$ is close to the negative ideal solution. Alternatives can be ranked according to the descending order of the value of $C_{k}^{+}$. 


$$
C_{k}^{+}=\frac{S_{k}^{-}}{S_{k}^{+}+S_{k}^{-}}, k=1,2, \cdots, n ; 0 \leq C_{k}^{+} \leq 1
$$

\section{The Proposed Multiple Criteria Risk Analysis Model}

The proposed model has interactive integration steps for three MCDM techniques named DEMATEL, ANP and TOPSIS. Interdependencies between criteria (risk factors) are determined by DEMATEL to construct the valid network structure that is the input of ANP. ANP is utilized to obtain the criteria weights. Thus, the relative importance of each risk factor is obtained. To find the precedence order for the workshops in the workplace to be utilized during the risk control stage TOPSIS comes handy. However TOPSIS does not provide criteria weights. From this viewpoint, this study combines ANP to determine the criteria weights and TOPSIS. The steps of the integrated model (Figure 1) are as follows:

Step 1) (DEMATEL Step 1, ANP Step 1, TOPSIS Step 1) Determine the criteria (risk factors), define them clearly via corporation between the risk assessment team and the analyst.

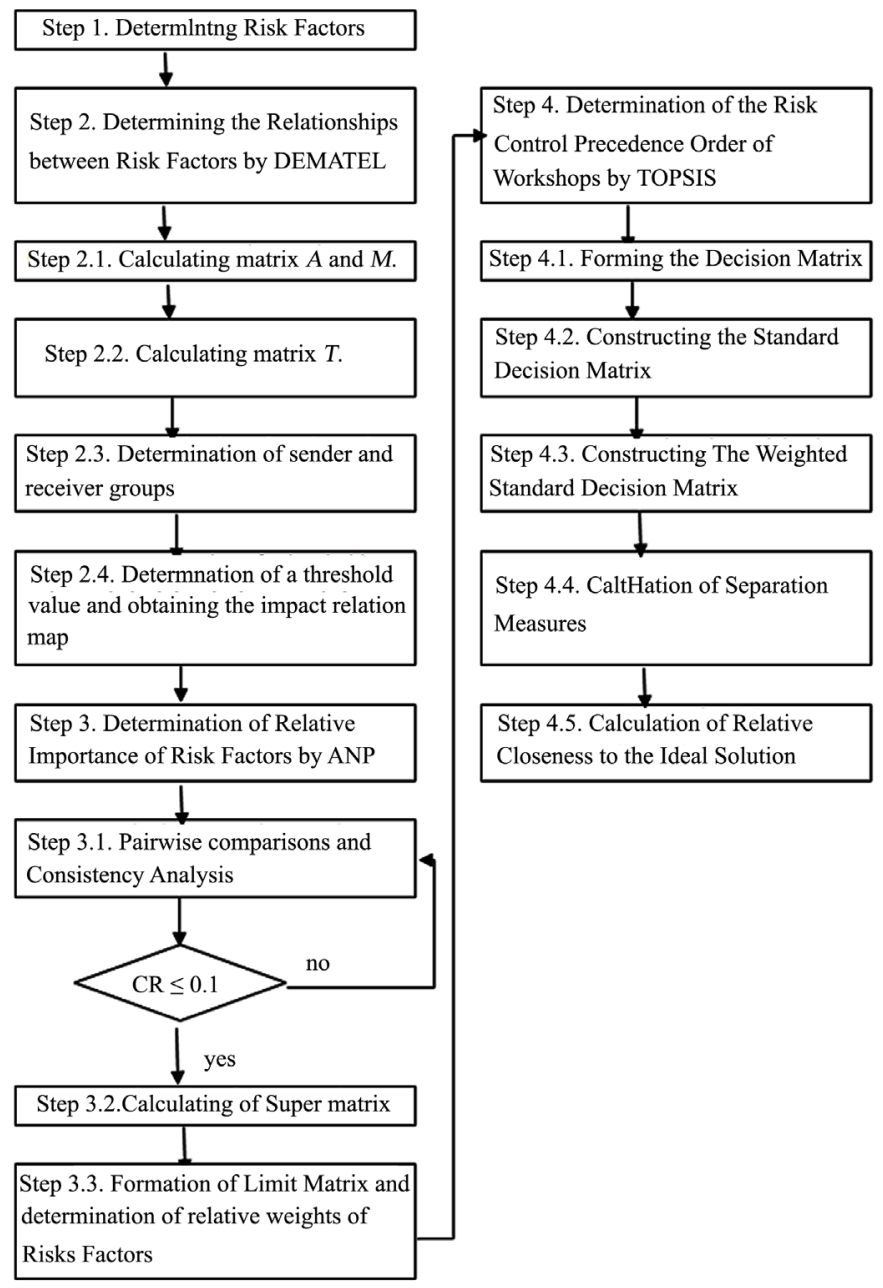

Figure 1. The multiple criteria risk analysis model. 
Step 2) (DEMATEL Step 2-3-4, ANP Step 1) Determine the relationship between criteria and construct the network structure for the selected criteria.

Step 3) (ANP Steps 2-3-4) Determine the weights for the criteria by pair-wise comparisons utilizing ANP. Check the consistency, and then revise the pair-wise comparisons; as needed.

Step 4) (TOPSIS whole steps) Construct the decision matrix with a goal of prioritizing the workshops based on the weighted criteria. Find the rank order of the workshops.

\section{Application Study}

The data for the application study is obtained from a workplace that produces order-based steel constructions such as elevators, chain conveyors, air belts, belts used in crushing and screening plants in metal industry. In the workplace 66 employees in manufacturing, 8 employees in paint, 2 employees sandblasting, 10 employees in the assembly process; 4 employees work in the field of shipment. The remaining 10 employees serve in the administrative department. Employees in the manufacturing process take part in assembly processes in case of requirement.

The numbers of occupational accidents occurred annually from year 2015 to 2018are 12, 19, 17 and 26 respectively based on the workplace records. During same years there is no fatal occupational accident. The environmental measurements are below the limit values (CSGB, 2009) specified in the legislation. The existing risk assessment team consisting of 5 people has difficulties in forming joint decisions. The risks in the workplace were leveled as acceptable risk, possible risk, significant risk, high risk and very high risk based on Fine-Kinney method. This method assesses the probability (probability of occurrence), frequency (frequency of exposure) and severity (estimated damage of the hazard) scale for a hazard. Because the identified hazards in the workplace have similar definitions; they are confused for employees and the risk assessment team members. Although overloading, overtime, shift work and inappropriate working conditions can cause work stress, psychosocial factors were not evaluated. Furthermore, the interrelations between risk factors are not considered.

The aim of the application study is to determine the risk factors/hazards that may cause work accidents and occupational diseases in the workplace, and to determine the order in which the workshops should be handled while taking the risk control measures. For this purpose, the proposed integrated MCDM approach is utilized for risk analysis. Firstly, the hazard elements/risk factors (criteria) that will cause occupational accidents and occupational diseases were determined and the relationships between the criteria were analyzed by DEMATEL method. After the criteria weights were determined by the ANP method, the TOPSIS method was used to rank the workshops according to risk. The flowchart summarizing the steps of the application is presented in Figure 1.

The implementation phase of the methods was carried out with 5 experts who 
are employer representative, occupational safety specialist, workplace physician and two employee representatives having 10 years of professional experience in the workplace. They have been working in the risk assessment team for 5 years. The method used to obtain the data is to form group decisions by conducting a survey study (Ciftci, 2019).

\subsection{Determination of Risk Factors}

The most important risk factors that may cause health and safety problems in the workplace are listed (CSGB, 2014a) as risk factors for accidents (working at height, working in explosive atmosphere, working with equipment), chemical and toxic substances (solvents, cleaners), physical factors (noise, vibration, thermal comfort conditions, lighting), dust, gas and fibers (welding fumes, silica powder, sawdust, asbestos fibers), biological factors (tetanus, viral hepatitis B and C, HIV/AIDS), ergonomic factors (incorrect working positions, repetitive movements, heavy load lifting), psycho-social factors (shortage of time, overtime, night work, conflict with chiefs).

When identifying hazards in a workplace, all aspects that could harm the employer and employees must be addressed. At this stage, hazards are determined by evaluating the factors such as occupational accident and occupational disease records, environmental measurements, production methods, activities, materials used, work equipment. Apart from the above mentioned common risk factors, there are many risk factors that employees may encounter in the work environment. Even in the workplaces where the same product is produced, different risks are encountered due to different production methods and forms, machinery and equipment and structural differences. There are different workplace-specific hazards due to the different activities, production processes, materials and machines used in each workplace (CSGB, 2014b). These hazards include hazards caused by working with electricity (e.g. ungrounded machines, faulty electrical installation, not insulating the floor, not periodically checking the electrical installation); mechanical hazards (e.g. absence of machine guards, failure of machines, periodic inspection and maintenance of machines); dangerous methods and processes (eg. deactivation of the machine guard, no PPE (Personal protective equipment), unsafe stacking of materials, failure to follow operating instructions); hazards arising from the workplace environment (for example, damaged workplace floor, irregular workplace, insufficient work area) are located.

In determining the risk factors to be used in the current study, the risk factors stated in TS 13740 standard (TSE, 2017) and the risk factors investigated in the second group of studies mentioned in the literature survey section, which concentrated on risk analysis and assessment applications and dealt with the practical needs of the companies in metal industry were taken into consideration. Furthermore, field observations, interviews with employees, risk assessment reports, occupational accident and near-incident records, workplace environment measurement results, health surveillance records were examined and evaluated 
by the risk assessment team. In this context, 8 main criteria and 30 sub-criteria that can cause occupational accidents and occupational diseases in the workplace have been determined. The investigation is conducted to evaluate the 3 workshops in the production area in the workplace. Table 1 contains the determined criteria by the risk assessment team.

Table 1. Risk factors (i.e. criteria) in the workplace.

$\begin{array}{r}\text { Criteria } \\ \hline \text { Physical Factors }\end{array}$

(K1)

Chemical Factors
(K2)

Electrical Source Factors

(K3)

\author{
Mechanical Factors \\ (K4)
}

Insecure Behaviors

(K5)

Factors arising from the
workplace environment
(K6)

Ergonomic Factors

(K7)

Psychosocial Factors

(K8)

\section{Sub-Criteria}

Noise (K11)

Vibration (K12)

Ventilation (K13)

Thermal comfort (K14)

Lighting (K15)

Toxic gas, smoke and vapor exposure (K21)

Chemical contact with skin or eye (K22)

Dust exposure (K23)

Ground (K31)

Status of electrical installation (K32)

Status of electrical panels (K33)

Periodic control and maintenance of work equipment (K41)

Machine/equipment status (K42)

Machine/equipment protectors (K43)

Status of control devices (K44)

Freight transport with work equipment (K51)

Comply with the operating instructions (K52)

Use of Personal Protective Equipment (PPE) (K53)

Material stacking (K54)

Order and cleanliness of the working environment (K61)

Condition of floors, ways and stairs (K62)

Warnings and warning signs (K63)

Emergency readiness (K64)

Repetitive movements (K71)

Improper working positions (K72)

Manual lifting transport (K73)

Work stress (K81)

Clarity of duties and responsibilities (K82)

Communication Level (K83)

Chiefs' support (K84) 


\subsection{Determination of the Relationships between Risk Factors by DEMATEL}

Matrix calculations for DEMATEL are obtained by Microsoft Excel. Step 2.1: The direct-relation matrix, $A$, is a square matrix of order 30 . The influence of each criterion is obtained by the arithmetic mean of the 5 experts' responses for each influence. The direct relationship matrix is given in the appendix. The normalized direct relation matrix, $M$, is obtained by Equation (1). Step 2.2: The total relation matrix, $T$ is obtained by Equation (2). Step 2.3: Table 2 shows the

Table 2. Sender and receiver groups of criteria.

\begin{tabular}{|c|c|c|c|c|c|c|}
\hline & Risk Factor & $R$ & $C$ & $R+C$ & $R-C$ & Sender/Receiver \\
\hline 1 & (K11) & 0.3024 & 0.3949 & 0.6972 & -0.0925 & Receiver \\
\hline 2 & (K12) & 0.2266 & 0.3591 & 0.5857 & -0.1325 & Receiver \\
\hline 3 & (K13) & 0.4386 & 0.2688 & 0.7074 & 0.1699 & Sender \\
\hline 4 & (K14) & 0.2031 & 0.1366 & 0.3397 & 0.0666 & Sender \\
\hline 5 & (K15) & 0.1278 & 0.0325 & 0.1603 & 0.1115 & Sender \\
\hline 6 & (K21) & 0.3466 & 0.5002 & 0.8468 & -0.1536 & Receiver \\
\hline 7 & (K22) & 0.1038 & 0.3228 & 0.4266 & -0.2190 & Receiver \\
\hline 8 & (K23) & 0.2791 & 0.4567 & 0.7357 & -0.1776 & Receiver \\
\hline 9 & (K31) & 0.1890 & 0.1736 & 0.3619 & 0.0146 & Sender \\
\hline 10 & (K32) & 0.2215 & 0.3074 & 0.5149 & -0.0999 & Receiver \\
\hline 11 & (K33) & 0.0674 & 0.1138 & 0.1808 & -0.0469 & Receiver \\
\hline 12 & (K41) & 0.6696 & 0.3288 & 0.9972 & 0.3397 & Sender \\
\hline 13 & (K42) & 0.5118 & 0.4487 & 0.9601 & 0.0626 & Sender \\
\hline 14 & (K43) & 0.1684 & 0.1720 & 0.3404 & -0.0036 & Receiver \\
\hline 15 & (K44) & 0.1717 & 0.1739 & 0.3456 & -0.0023 & Receiver \\
\hline 16 & (K51) & 0.1561 & 0.5769 & 0.7329 & -0.4207 & Receiver \\
\hline 17 & (K52) & 1.1044 & 0.2090 & 1.3133 & 0.8954 & Sender \\
\hline 18 & (K53) & 0.7133 & 0.3109 & 1.0242 & 0.4023 & Sender \\
\hline 19 & (K54) & 0.1984 & 0.1422 & 0.3405 & 0.0562 & Sender \\
\hline 20 & (K61) & 0.2442 & 0.2342 & 0.4784 & 0.0100 & Sender \\
\hline 21 & (K62) & 0.1556 & 0.1612 & 0.3167 & -0.0054 & Receiver \\
\hline 22 & (K63) & 0.5963 & 0.1240 & 0.7199 & 0.4721 & Sender \\
\hline 23 & (K64) & 0.2261 & 0.4782 & 0.7040 & -0.2524 & Receiver \\
\hline 24 & (K71) & 0.1770 & 0.2314 & 0.4084 & -0.0544 & Receiver \\
\hline 25 & (K72) & 0.1908 & 0.3435 & 0.5343 & -0.1525 & Receiver \\
\hline 26 & (K73) & 0.2431 & 0.2036 & 0.4467 & 0.0396 & Sender \\
\hline 27 & (K81) & 0.1018 & 1.2706 & 1.3724 & -1.1677 & Receiver \\
\hline 28 & (K82) & 0.3111 & 0.2615 & 0.5726 & 0.0497 & Sender \\
\hline 29 & (K83) & 0.3042 & 0.2914 & 0.5956 & 0.0128 & Sender \\
\hline 30 & (K84) & 0.3971 & 0.1188 & 0.5158 & 0.2783 & Sender \\
\hline
\end{tabular}


calculations related with the determination of the sender and receiver groups of risk factors. A high $r_{i}+c_{j}$, value of a criterion $\forall i=j$ shows that it has a high relationship with other criteria.

Based on the $R+C$ column in Table 2 bold case numbers indicates the criteria which are work stress (K81) with 1.3724 value, comply with the operating work instructions (K52) with 1.3133 value, use of PPE (K53) with 1.0242 value, periodic control and maintenance of work equipment (K41) with 0.9972 value, and machine/equipment status (K42) with 0.9601 value have high correlation with other criteria in the workplace. If a $r_{i}-c_{j}$, value of a criterion $\forall i=j$ is positive, it affects the other criteria, it is a cause (sender) and if it is negative, it is affected by other criteria; it is an effect (receiver).

It is observed (Table 2) that the criteria of comply with the operating work instructions (K52), warnings and warning signs (K63) use of PPE (K53) affect other criteria more; the work stress (K81), freight transport with work equipment (K51), and emergency readiness (K64) are affected more. Step 2.4: Determination of a threshold value and obtaining the Network Relation Map. The threshold value $(\alpha)$ is determined as 0.0173 by the risk assessment team so as not to ignore the interaction between the criterion ventilation (K12) and use of PPE (K53) and the periodic control and maintenance of work stress and work equipment (K41). The Network Relation Map represents the network structure of interrelated risk factors. These interrelations are represented by the influence matrix in Table 3, which is obtained based on $R+C$ and $R-C$ values.

\subsection{Determination of Relative Importance of Risk Factors by ANP}

The relationships between the criteria (Table 3) are the input of ANP and they are utilized to construct network structure between risk factors. A pairwise comparison questionnaire was conducted among 5 experts and the group decision is determined by the geometrical averages of the expert responses based on Saaty's (Saaty, 2004) nine point scales. Super Decision

(http://www.superdecisions.com/) software was utilized for the application of ANP.

When entering data of the pairwise comparisons of risk factors in the Super Decision program, "the node" option is chosen for the sub-criteria and" the cluster option" is chosen for the main criteria. The consistency ratio is less than 0.10 . The weight of each factor is obtained by the limited super-matrix. Table 4 gives the summary of the software outputs.

The top 10 risk factors (Table 4) are "comply with the operating instructions (K52)", "emergency readiness (K64)", "warnings and warning signs (K63)", "use of PPE (K53)", "status of electrical installations (K32)", "periodic control and maintenance of work equipment (K41)", "clarity of duties and responsibilities (K82)", "work stress (K81)", "freight transport with work equipment (K51)" and "machine/equipment status (K42)". Among these 10 sub-criteria, 3 of them are 
Table 3. Influence matrix for ANP.

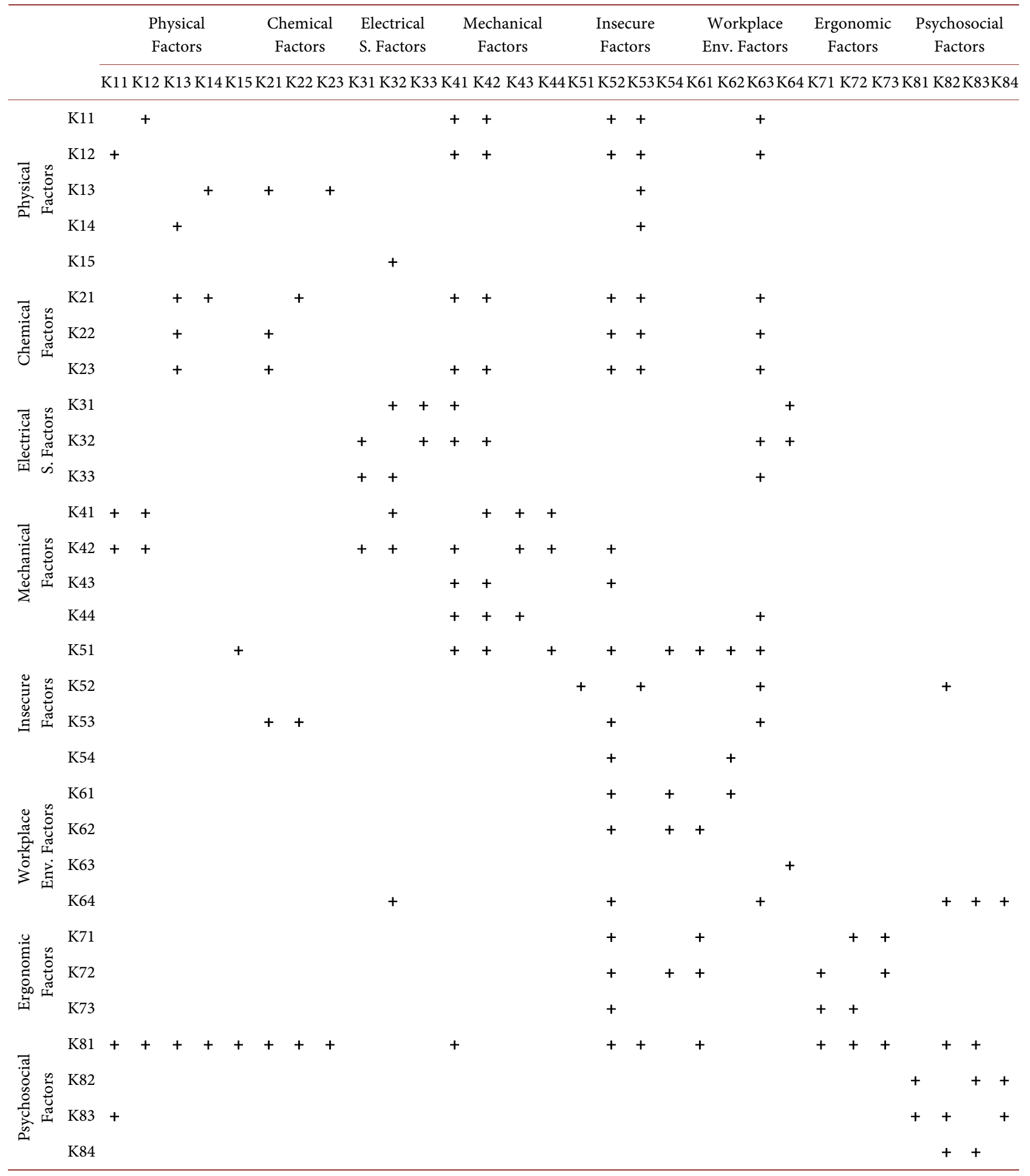

classified under the main criteria "insecure behaviors (K5)", 2 of them are classified under the main criteria "environmental factors arising from workplace (K6)", 2 of them are classified under the main criteria" mechanical factors (K4)", 2 of them are classified under the main criteria "psychosocial factors (K8)". 
Table 4. Weights of criteria/risk factors.

\begin{tabular}{|c|c|c|c|c|c|}
\hline Criteria & Sub-Criteria & Local Weights & Global Weights & Global Weights (\%) & Priorities \\
\hline \multirow{5}{*}{ K1 } & K11 & 0.6356 & 0.0285 & 2.85 & 12 \\
\hline & K12 & 0.2374 & 0.0106 & 1.06 & 18 \\
\hline & K13 & 0.076 & 0.0034 & 0.34 & 26 \\
\hline & K14 & 0.0404 & 0.0018 & 0.18 & 29 \\
\hline & K15 & 0.0105 & 0.0004 & 0.04 & 30 \\
\hline \multirow{3}{*}{ K2 } & $\mathrm{K} 21$ & 0.461 & 0.0083 & 0.83 & 22 \\
\hline & K22 & 0.3627 & 0.0065 & 0.65 & 23 \\
\hline & K23 & 0.1763 & 0.0032 & 0.32 & 27 \\
\hline \multirow{3}{*}{ K3 } & K31 & 0.2756 & 0.0283 & 2.83 & 13 \\
\hline & K32 & 0.5413 & 0.0556 & 5.56 & 5 \\
\hline & K33 & 0.1831 & 0.0188 & 1.88 & 15 \\
\hline \multirow{4}{*}{$\mathrm{K} 4$} & K41 & 0.4917 & 0.0536 & 5.36 & 6 \\
\hline & K42 & 0.3009 & 0.0328 & 3.28 & 10 \\
\hline & K43 & 0.0887 & 0.0096 & 0.96 & 21 \\
\hline & K44 & 0.1187 & 0.0129 & 1.29 & 17 \\
\hline \multirow{4}{*}{ K5 } & K51 & 0.1252 & 0.0366 & 3.66 & 9 \\
\hline & K52 & 0.5284 & 0.1545 & 15.45 & 1 \\
\hline & K53 & 0.2981 & 0.0872 & 8.72 & 4 \\
\hline & K54 & 0.0482 & 0.0141 & 1.41 & 16 \\
\hline \multirow{4}{*}{ K6 } & K61 & 0.0368 & 0.0102 & 1.02 & 19 \\
\hline & K62 & 0.0364 & 0.0101 & 1.01 & 20 \\
\hline & K63 & 0.4533 & 0.1260 & 12.6 & 3 \\
\hline & K64 & 0.4735 & 0.1316 & 13.16 & 2 \\
\hline \multirow{3}{*}{ K7 } & K71 & 0.1677 & 0.0023 & 0.23 & 28 \\
\hline & K72 & 0.3706 & 0.0051 & 0.51 & 25 \\
\hline & K73 & 0.4616 & 0.0064 & 0.64 & 24 \\
\hline \multirow{4}{*}{ K8 } & K81 & 0.2901 & 0.0408 & 4.08 & 8 \\
\hline & K82 & 0.3102 & 0.0437 & 4.37 & 7 \\
\hline & K83 & 0.2288 & 0.0322 & 3.22 & 11 \\
\hline & K84 & 0.1708 & 0.0240 & 2.4 & 14 \\
\hline
\end{tabular}

\subsection{Determination of the Risk Control Precedence Order of Workshops by TOPSIS}

A questionnaire was conducted among experts to determine a risk precedence 
order of three workshops based on the risk factors. The group decision is determined by geometrical averages of the expert responses based on $1-10$ scale from less to high risk levels and the decision matrix is constructed in Table 5. The original $3 \times 30$ sized decision matrix is represented by $3 \times 15$ sized two matrices in Table 5. Matrix calculations for TOPSIS are obtained by Microsoft Excel. The normalized $\left(R_{3 \times 30}\right)$ and weighted normalized $\left(V_{3 \times 30}\right)$ decision matrices are built up based on Equations (6) and (7). Ideal $\left(A^{+}\right)$and negative ideal $\left(A^{-}\right)$solutions are calculated by using Equations (8)-(9).

$A^{*}=(0.42 ; 0.16 ; 0.04 ; 0.03 ; 0.01 ; 0.08 ; 0.08 ; 0.03 ; 0.52 ; 0.43 ; 0.18 ; 0.53 ; 0.28 ; 0.1 ;$ $0.2 ; 0.41 ; 0.81 ; 0.45 ; 0.09 ; 0.07 ; 0.15 ; 1,52 ; 2,12 ; 0.02 ; 0.04 ; 0.06 ; 0.38 ; 0.6 ; 0.56$; $0.42)$

$A^{-}=(0.14 ; 0.08 ; 0.02 ; 0.01 ; 0 ; 0.01 ; 0.02 ; 0.02 ; 0.28 ; 0.23 ; 0.14 ; 0.18 ; 0.18 ; 0.03 ;$ $0.11 ; 0.14 ; 0.7 ; 0.33 ; 0.08 ; 0.05 ; 0.04 ; 1.00 ; 1.53 ; 0.01 ; 0.03 ; 0.04 ; 0.28 ; 0.33 ; 0.41$; $0.34)$

The separation from the ideal solution $\left(S_{k}^{+}\right)$and from the negative-ideal solution $\left(S_{k}^{-}\right)$are calculated by Equations (10) and (11) respectively. Relative closeness $\left(C_{k}^{+}\right)$to ideal solution is calculated based on Equation (12) for workshops according to their ideal and negative ideal solutions. According to founded relative closeness, the workshops are ranked in Table 6.

Table 5. (a) First part of the decision matrix $D=\left[x_{k j}\right], k=1,2,3$ and $j=1,2, \cdots, 15$ in TOPSIS; (b) Second part of the decision matrix $D=\left[x_{k j}\right], k=1,2,3$ and $j=16,17, \cdots, 30$ in TOPSIS.

(a)

\begin{tabular}{lllllllllllllllllll}
\hline & K11 & K12 & K13 & K14 & K15 & K21 & K22 & K23 & K31 & K32 & K33 & K41 & K42 & K43 & K44 \\
\hline A1 & 4.96 & 3.73 & 4.13 & 3.57 & 1.32 & 4.78 & 3.78 & 4.74 & 2.49 & 5.38 & 3.52 & 4.37 & 4.78 & 5.38 & 2.55 \\
A2 & 2.55 & 1.74 & 3.37 & 1.52 & 3.18 & 5.75 & 3.95 & 4.18 & 2.35 & 6.55 & 4.54 & 2.17 & 3.37 & 1.74 & 2.00 \\
A3 & 1.64 & 2.70 & 2.17 & 2.77 & 1.74 & 1.00 & 1.00 & 2.17 & 1.32 & 3.57 & 3.73 & 6.38 & 5.14 & 4.54 & 3.64 \\
\hline
\end{tabular}

(b)

\begin{tabular}{llllllllllllllllll}
\hline & K51 & K52 & K53 & K54 & K61 & K62 & K63 & K64 & K71 & K72 & K73 & K81 & K82 & K83 & K84 \\
\hline A1 & 2.93 & 6.76 & 7.79 & 6.09 & 6.19 & 5.38 & 3.57 & 2.77 & 5.14 & 4.37 & 4.37 & 4.57 & 3.95 & 2.55 & 2.17 \\
A2 & 2.35 & 6.38 & 7.58 & 5.38 & 5.38 & 1.32 & 3.37 & 2.35 & 3.57 & 3.78 & 3.57 & 4.13 & 2.93 & 2.17 & 2.17 \\
A3 & 6.79 & 7.38 & 5.70 & 5.38 & 4.37 & 2.55 & 2.35 & 2.00 & 5.58 & 5.58 & 5.75 & 3.29 & 2.17 & 1.89 & 1.74 \\
\hline
\end{tabular}

Table 6. Separation measures, relative closeness and precedence order of workshops.

\begin{tabular}{cccccc}
\hline Workshop & $S_{k}^{+}$ & $S_{k}^{-}$ & $C_{k}^{+}$ & $(\%)$ & Order \\
\hline Manufacturing & 0.32 & 0.98 & 0.76 & 48 & 1 \\
Painting & 0.66 & 0.63 & 0.49 & 31 & 2 \\
Assembly & 0.97 & 0.48 & 0.33 & 21 & 3 \\
\hline
\end{tabular}




\section{Results and Discussion}

In the study, 30 risk factors that may cause occupational accidents and occupational diseases were identified as hazard factors in metal industry. Determination procedure considers OHS risk assessment regulations in the country, the risk assessment studies in the open literature on metal industry and the risk factors mentioned in TS 13740 (TSE, 2017) for metal industry and combine them the expertise and knowledge of the risk assessment team. In the first stage of the study, DEMATEL method reveals (Table $2,(R+C)$ column) that "periodic control and maintenance of work equipment (K41)", "machine/equipment status (K42)" "comply with the operating instructions (K52)", use of PPE (K53), and "work stress (K81)" have high relationships with other criteria in the workplace. When the impact aspects of the criteria are examined; it is observed (Table 2, $(R$ $-C$ column) that the criteria of "comply with the operating work instructions (K52)", "warnings and warning signs (K63)", "use of PPE (K53)" affect other criteria more; the criteria of "work stress (K81)", "freight transport with work equipment (K51)", and "emergency readiness (K64)" are affected more.

Based on DEMATEL method, the criteria of "comply with the operating instructions (K52)", "emergency readiness (K64)" are influenced by "clarity of duties and responsibilities (K82)", "communication level (K83)" and "chiefs' support (K84)" that is placed in psychosocial factors. The criteria of "comply with the operating instructions (K52)", "use of PPE (K53)", "periodic control and maintenance of work equipment (K41)" affects "work stress (K81)". In addition, all sub-criteria under "physical", "chemical" and "ergonomic" factors were found to be effective on the occurrence of "work stress (K81)".

The first 5 "risk factors (criteria code)" with (global weight percentage mentioned in Table 4) having the highest severity according to ANP method are "comply with the operating instructions (K52)" with (15.45\%), "emergency readiness (K64)" with (13.16\%), "warning and warning signs (K63)" with (12.6\%), "use of PPE with (K53)" (8.72\%) and "status of the electrical installation with (K32)" with (5.56\%). These 5 criteria have an impact on the incidence of occupational accidents and occupational diseases in the workplace within a total of $55.49 \%$. Evaluation results show that the main criterion "insecure behaviors" coded K5 and the main criterion "factors arising from workplace environment" coded $\mathrm{K} 6$ are more important in terms of OHS in the workplace. These criteria are followed by "periodic control and maintenance of work equipment (K41)" with (5.36\%), "clarity of duties and responsibilities (K82)" with $(4,37 \%)$ and "work stress" (K81) with (4.08\%).

The previous risk assessment study in the workplace did not consider the psychosocial factors and ignored the relationships between the risk factors. The proposed risk analysis reveals that hazard factors have relations to each other and these relationships were effective on the importance levels of the hazards. The proposed risk analysis shows that the psychosocial factors have remarkable high importance. 
Although OHS activities must be carried out simultaneously in each section of the workplaces, in practical applications executer need to make a decision to take precaution. At the last stage of the study, the criteria weights determined by the ANP method were used as input in the TOPSIS method and 3 workshops were made in the workplace. As a result of the analysis carried out by TOPSIS method, it was determined that when the workplace was evaluated in terms of factors causing occupational accidents and occupational diseases, precautions should be taken in manufacturing, painting and assembly workshops respectively.

\section{Conclusion and Future Directions}

Risk analysis has strict effects on the quantitative and qualitative outputs of the OHS system. Valid and effective risk assessment should proper the needs of the industry and the problem specific requirements which are vital to guarantee/develop a well working OHS system. In order to reach the most appropriate results, the current study proposed a multiple criteria risk analysis model and utilized it for the solution of an OHS risk analysis problem in metal industry. The proposed risk analysis model is an integrated multi criteria decision making approach. It takes into consideration of all the risk factors as criteria that affect the risk analysis problem and also the relations of these risk criteria with each other. The approach has the ability to involve a large number of individuals in the decision-making process to bring their expertise and knowledge together and express them in a valid and mathematically effective way for the benefit of the problem solution.

The 30 risk factors identified in this study offer handy sources for future risk assessment studies in metal industry. However, considering the specific product and production processes of each enterprise, risk factors can be revised by adding or qualifying to the criteria determined in this study.

The detailed literature review reveals that the current study is the first one which utilizes DEMATEL-ANP integrated approach in metal industry and it provides a guide to perform DEMATEL-AHP-TOPSIS integrated method for risk analysis. DEMATEL-ANP integration helps the analyst and the risk assessment team to reach the valid and effective risk assessment by developing the interrelationships between risk factors. Integration of TOPSIS suggests a precedence order for the workshops for the risk control activities.

Psychosocial risk assessment is becoming increasingly important for research and OHS due to legislative amendments obliging employers to implement psychosocial work factors into general risk assessment (Metzler et al., 2019). The current study considers the psychosocial factors beside the traditional risk factors.

The findings of the study offer fruitful inspirations to the managers in metal industry and the approach is believed to have a wide range of applications for risk assessment and analysis in the field of OHS. 
The proposed risk analysis model can be utilized for different sectors and also can be revised based on proper different multiple criteria methods.

\section{Acknowledgements}

The authors are grateful to the anonymous referees for their valuable comments on improving the manuscript.

\section{Conflicts of Interest}

The authors declare no conflicts of interest regarding the publication of this paper.

\section{References}

Aminbakhsh, S., Gunduz, M., \& Sonmez, R. (2013). Safety Risk Assessment Using Analytic Hierarchy Process (AHP) during Planning and Budgeting of Construction Projects. Journal of Safety Research, 46, 99-105. https://doi.org/10.1016/j.jsr.2013.05.003

Andersen, L. P., Kines, P., \& Hasle, P. (2007). Owner Attitudes and Self-Reported Behavior towards Modified Work after Occupational Injury Absence in Small Enterprises: A Qualitative Study. Journal of Occupational Rehabilitation, 17, 107-121. https://doi.org/10.1007/s10926-007-9064-5

Aven, T. (2010). On the Need for Restricting the Probabilistic Analysis in Risk Assessments to Variability. Risk Analysis, 30, 354-360. https://doi.org/10.1111/j.1539-6924.2009.01314.x

Aven, T. (2011). Quantitative Risk Assessment. The Scientific Platform. Cambridge: Cambridge University Press. https://doi.org/10.1017/CBO9780511974120

Aven, T. (2016). Risk Assessment and Risk Management: Review of Recent Advances on Their Foundation. European Journal of Operational Research, 253, 1-13. https://doi.org/10.1016/j.ejor.2015.12.023

Aven, T., \& Heide, B. (2009). Reliability and Validity of Risk Analysis. Reliability Engineering and System Safety, 94, 1862-1868. https://doi.org/10.1016/j.ress.2009.06.003

Ciftci, S. E. (2019). Multiple Criteria Risk Analysis for a Plant in Metal Industry. M.Sc. Thesis, Ankara: Gazi University.

CSGB (Rebublic of Turkey the Ministry of Family, Labor and Social Services) (2009). OHS Directory for Workplaces in Metal Sector, Improving Labour Inspection Sytem Project Report. https://ailevecalisma.gov.tr/medias/5993/2009 31.pdf

CSGB (Rebublic of Turkey the Ministry of Family, Labor and Social Services) (2014a). OHS Management Guide for SMEs: Metal Sector. http://www.isgip.gov.tr/wp-content/uploads/2015/11/isgip metal 1 rehber.pdf

CSGB (Republic of Turkey the Ministry of Family, Labor and Social Services) (2014b). OHS Management Guide for SMEs: Risk Assessment, OHS Performance Monitoring and Health Hazards: Metal Sector. http://www.isgip.gov.tr/wp-content/uploads/2015/11/isgip metal 2 RA.pdf

Dabbagh, R., \& Yousefi, S. (2019). A Hybrid Decision-Making Approach Based on FCM and MOORA for Occupational Health and Safety Risk Analysis. Journal of Safety Research, 71, 111-123. https://doi.org/10.1016/j.jsr.2019.09.021

Dehdasht, G., Zin, R. M., Ferwati, M. S., Abdullahi, M. M., Ali Keyvanfar, A., \& McCaffer, 
R. (2017). DEMATEL-ANP Risk Assessment in Oil and Gas Construction Projects. Sustainability, 9, 1420-1444. https://doi.org/10.3390/su9081420

ECAST (The European Commercial Aviation Safety Team) (2009). Guidance on Hazards Identification.

https://www.easa.europa.eu/sites/default/files/dfu/ECASTSMSWG-GuidanceonHazard Identification1.pdf

EEC (European Economic Community) (1989). Council Directive 89/391/EEC of 12 June 1989 on the Introduction of Measures to Encourage Improvements in the Safety and Health of Workers at Work. https://eur-lex.europa.eu/legal-content/EN/ALL/?uri=CELEX\%3A31989L0391

Fargnoli, M., Lombardi, M., Puri, D., Casorri, L., Masciarelli, E., Mandic-Rajcevic, S., \& Colosio, C. (2019). The Safe Use of Pesticides: A Risk Assessment Procedure for the Enhancement of OHS Management. International Journal of Environmental Research and Public Health, 16, 310. https://doi.org/10.3390/ijerph16030310

Fazli, S., Mavi, R. K., \& Vosooghidizaji, M. (2015). Crude Oil Supply Chain Risk Management with DEMATEL-ANP. Operational Research: An International Journal, 15, 453-480. https://doi.org/10.1007/s12351-015-0182-0

Goerlandt, F., Khakzad, N., \& GenserikReniers, G. (2017). Validity and Validation of Safety-Related Quantitative Risk Analysis: A Review. Safety Science, 99, 127-139. https://doi.org/10.1016/j.ssci.2016.08.023

Gul, M. (2018). A Review of OHS Risk Assessment Approaches Based on Multi-Criteria Decision-Making Methods and Their Fuzzy Versions. Human and Ecological Risk Assessment, 24, 1723-1760. https://doi.org/10.1080/10807039.2018.1424531

Harms-Ringdahl, L. (2001). Safety Analysis: Principles and Practice in Occupational Safety (2nd ed.). London: Taylor \& Francis. https://doi.org/10.4324/9780203302736

Hasle, P., Kines, P., \& Andersen, L. P. (2009). Small Enterprise Owners' Accident Causation Attribution and Prevention. Safety Science, 47, 9-19.

https://doi.org/10.1016/j.ssci.2007.12.005

Hatefi, S. M., \& Tamosaitiene, J. (2019). An Integrated Fuzzy DEMATEL-Fuzzy ANP Model for Evaluating Construction Projects by Considering Interrelationships among Risk Factors. Journal of Civil Engineering and Management, 25, 114-131. https://doi.org/10.3846/jcem.2019.8280

Health and Safety Laboratory (2000). Review of Hazard Identification Techniques, HSL/2005/58. https://www.hse.gov.uk/research/hsl_pdf/2005/hsl0558.pdf

Hwang, C. L., \& Yoon, K. (1981). Multi Attribute Decision Making Methods and Applications a State of the Art Survey. New York: Springer-Verlag. https://doi.org/10.1007/978-3-642-48318-9 3

Ilangkumaran, M., Karthikeyan, M., Ramachandran, T., Boopathiraja, M., \& Kirubakaran, B. (2015). Risk Analysis and Warning Rate of Hot Environment for Foundry Industry Using Hybrid MCDM Technique. Safety Science, 72, 133-143. https://doi.org/10.1016/j.ssci.2014.08.011

Jacinto, C., \& Aspinwall, E. (2004). A Survey on Occupational Accidents' Reporting and Registration Systems in the European Union. Safety Science, 42, 933-960. https://doi.org/10.1016/j.ssci.2004.07.002

Kines, P., Andersen, D., Andersen, L. P., Nielsen, K., \& Pedersen, L. (2013). Improving Safety in Small Enterprises through an Integrated Safety Management Intervention. Journal of Safety Research, 44, 87-95. https://doi.org/10.1016/j.jsr.2012.08.022

Kubler, S., Robert, J., Derigent, W., Voisin, A., \& Traon, Y. L. (2016). A State-of the-Art 
Survey \& Testbed of Fuzzy AHP (FAHP) Applications. Expert Systems with Applications, 65, 398-422. https://doi.org/10.1016/j.eswa.2016.08.064

Laitinen, H., Vuorinen, M., Simola, A., \& Yrjanheikki, E. (2013). Observation-Based Proactive OHS Outcome Indicators-Validity of the Elmeri+ Method. Safety Science, 54, 69-79. https://doi.org/10.1016/j.ssci.2012.11.005

Mahdevari, S., Shahriar, K., \& Esfahanipour, A. (2014). Human Health and Safety Risks Management in Underground Coal Mines Using Fuzzy TOPSIS. Science Total Environment, 488, 85-99. https://doi.org/10.1016/j.scitotenv.2014.04.076

Metzler, Y. A., Groeling-Mullerb, G., \& Bellingratha, S. (2019). Better Safe than Sorry: Methods for Risk Assessment of Psychosocial Hazards. Safety Science, 114, 122-139. https://doi.org/10.1016/j.ssci.2019.01.003

Pasman, H. J., Jung, S., Prem, K., Rogers, W. J., \& Yang, X. (2009). Is Risk Analysis a Useful Tool for Improving Process Safety? Journal of Loss Prevention in the Process Industries, 22, 769-777. https://doi.org/10.1016/j.jlp.2009.08.001

Rae, A., Alexander, R., \& McDermid, J. (2014). Fixing the Cracks in the Crystal Ball: A Maturity Model for Quantitative Risk Assessment. Reliability Engineering and System Safety, 125, 67-81. https://doi.org/10.1016/j.ress.2013.09.008

Rajala, H. K., \& Vayrynen, S. (2010). Constructing Core Stories for Contributing Practical Safety Actions in Industrial Units. Safety Science, 48, 1393-1401. https://doi.org/10.1016/j.ssci.2010.05.014

Reinhold, K., \& Pallon, L. (2014). Metal Workers: Exposure to Chemicals and Noise Caused by Using Incorrect Safety Measures. Iranian Journal of Public Health, 43, 186-193.

Robson, L. S., Clarke, J. A., Cullen, K., Bielecky, A., Severin, C., Bigelow, P. L., Irvin, E., Culyer, A., \& Mahood, Q. (2007). The Effectiveness of OHS Management System Interventions: A Systematic Review. Safety Science, 45, 329-353.

https://doi.org/10.1016/j.ssci.2006.07.003

Rosqvist, T. (2010). On the Validation of Risk Analysis-A Commentary. Reliability Engineering and System Safety, 95, 1261-1265. https://doi.org/10.1016/j.ress.2010.06.002

Saaty, T. L. (2004). Fundamentals of the Analytic Network Process-Dependence and Feedback in Decision-Making with a Single Network. Journal of Systems Science and Systems Engineering, 13, 129-157. https://doi.org/10.1007/s11518-006-0158-y

Saaty, T. L., \& Vargas, L. G. (2006). Decision Making with the Analytic Network Process Economic, Political, Social and Technological Applications with Benefits, Opportunities, Cost and Risks. New York: Springer Science Business Media, LLC.

Samantra, C., Datta, S., \& Mahapatra, S. S. (2017). A Risk-Based Decision Support Framework for Selection of Appropriate Safety Measure System for Underground Coal Mines. International Journal of Injury Control and Safety Promotion, 24, 54-68. https://doi.org/10.1080/17457300.2015.1061561

Shih, H. S., Shyur, H. J., \& Lee, S. E. (2007). An Extension of TOPSIS for Group Decision Making. Mathematical and Computer Modeling, 45, 801-813. https://doi.org/10.1016/j.mcm.2006.03.023

Silva, S. L. C., \& Amaral, F. G. (2019). Critical Factors of Success and Barriers to the Implementation of OHS Management Systems: A Systematic Review of Literature. Safety Science, 117, 123-132. https://doi.org/10.1016/j.ssci.2019.03.026

Silvestri, A., Felice, F., \& Antonella Petrillo, A. (2012). Multi-Criteria Risk Analysis to Improve Safety in Manufacturing Systems. International Journal of Production Research, 50, 4806-4821. https://doi.org/10.1080/00207543.2012.657968 
Tixier, J., Dusserre, G., Salvi, O., \& Gaston, D. (2002). Review of 62 Risk Analysis Methodologies of Industrial Plants. Journal of Loss Prevention in the Process Industries, 15, 291-303. https://doi.org/10.1016/S0950-4230(02)00008-6

TSE (Turkish Standards Institution) (2017). TS 13740 OHS Management System-For Small and Medium Sized Enterprises (SMEs) - Metal Sector in Turkish, Ankara (pp. 1-34).

Tzeng, G. H., \& Huang, J. J. (2011). Multi Attribute Decision Making: Methods and Applications. Boca Raton, FL: CRC Press. https://doi.org/10.1201/b11032

Tzeng, G. H., Chiang, C. H., \& Li, C. W. (2007). Evaluating Intertwined Effects in E-Learning Programs: A Novel Hybrid MCDM Model Based on Factor Analysis and Dematel. Expert Systems with Applications, 32, 1028-1044.

https://doi.org/10.1016/j.eswa.2006.02.004

Welch, L. S., Haile, E., Dement, J., \& Michaels, D. (2007). Change in Prevalence of Asbestos-Related Disease among Sheet Metal Workers 1986 to 2004. Environmental Health, 131, 863-869. https://doi.org/10.1378/chest.06-1155

Yilmaz, N., \& veSenol, M. B. (2017). A Model and Application of OHS Risk Assessment. Journal of the Faculty of Engineering and Architecture of Gazi University, 32, 77-87. 
Appendix: The Direct Relation Matrix $A=\left[a_{i j}\right], i, j=1,2, \cdots, 30$, in DEMATEL

K11 K12 K13 K14 K15 K21 K22 K23 K31 K32 K33 K41 K42 K43 K44 K51 K52 K53 K54 K61 K62 K63 K64 K71 K72 K73 K81 K82 K83 K84

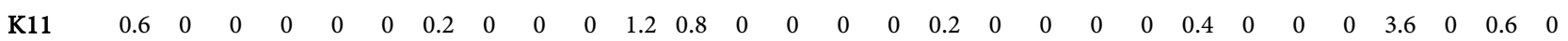

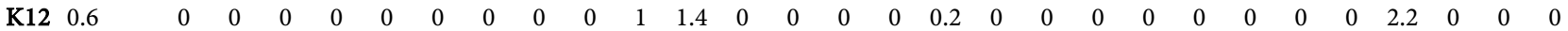
$\begin{array}{llllllllllllllllllllllllllllllll}\mathrm{K} 13 & 0 & 0 & 1.8 & 0 & 3 & 0.8 & 2.8 & 0 & 0 & 0 & 0 & 0 & 0 & 0 & 0 & 0 & 0 & 0 & 0 & 0 & 0 & 0 & 0 & 0 & 0 & 3.2 & 0 & 0 & 0\end{array}$ $\begin{array}{llllllllllllllllllllllllllllllll}\mathrm{K} 14 & 0 & 0 & 1.2 & 0 & 0.8 & 0 & 0 & 0 & 0 & 0 & 0 & 0 & 0 & 0 & 0 & 0 & 0.4 & 0 & 0 & 0 & 0 & 0 & 0 & 0 & 0 & 2.8 & 0 & 0 & 0\end{array}$

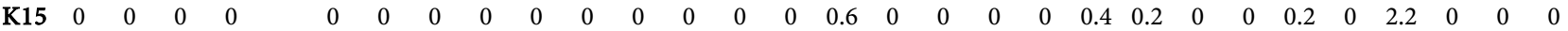
$\begin{array}{lllllllllllllllllllllllllllllll}\mathrm{K} 21 & 0 & 0 & 2.2 & 0.2 & 0 & 1.8 & 0.4 & 0 & 0 & 0 & 0.4 & 0.4 & 0 & 0 & 0 & 0 & 0.6 & 0 & 0 & 0 & 0.2 & 0.4 & 0 & 0 & 0 & 2 & 0 & 0 & 0\end{array}$

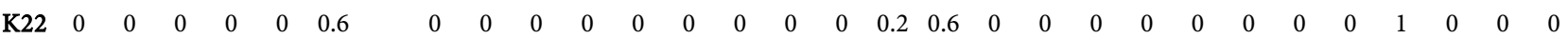
$\begin{array}{llllllllllllllllllllllllllllllll}\mathrm{K} 23 & 0 & 0 & 2.6 & 0 & 0 & 0 & 0 & & 0 & 0 & 0 & 0.4 & 0.4 & 0 & 0 & 0 & 0 & 0.4 & 0 & 0 & 0 & 0.4 & 0.4 & 0 & 0 & 0 & 2 & 0 & 0 & 0\end{array}$ K31 $00 \begin{array}{llllllllllllllllllllllllllllll} & 0 & 0 & 0 & 0 & 0 & 0 & 0 & & 1.8 & 1.2 & 0.2 & 1.2 & 0 & 0 & 0 & 0 & 0 & 0 & 0 & 0 & 0 & 0.4 & 0 & 0 & 0 & 0 & 0 & 0 & 0\end{array}$ K32 $0 \begin{array}{lllllllllllllllllllllllllllllll}0 & 0 & 0 & 0 & 0.6 & 0 & 0 & 0 & 1.4 & 0.8 & 0.6 & 1 & 0 & 0.2 & 0 & 0 & 0 & 0 & 0 & 0 & 0 & 1 & 0 & 0 & 0 & 0 & 0 & 0 & 0\end{array}$ K33 $00 \begin{array}{llllllllllllllllllllllllllllll} & 0 & 0 & 0 & 0 & 0 & 0 & 0 & 0.6 & 1 & 0 & 0 & 0 & 0 & 0 & 0 & 0 & 0 & 0 & 0 & 0 & 0.2 & 0 & 0 & 0 & 0 & 0 & 0 & 0\end{array}$

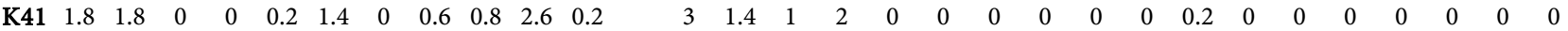

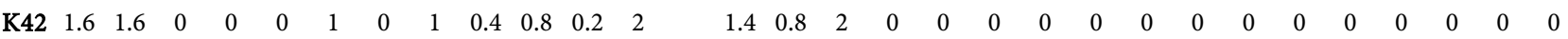
K43 $00 \begin{array}{llllllllllllllllllllllllllllll} & 0 & 0 & 0 & 0 & 0.2 & 0.4 & 0.2 & 0 & 0 & 0 & 0.8 & 1 & & 1.2 & 0.2 & 0 & 0 & 0 & 0 & 0 & 0 & 0 & 0 & 0 & 0 & 0 & 0 & 0 & 0\end{array}$ K44 $00 \begin{array}{lllllllllllllllllllllllllllllll} & 0 & 0 & 0 & 0 & 0 & 0 & 0 & 0 & 0 & 0 & 0.8 & 0.8 & 0.4 & 2.2 & 0 & 0 & 0 & 0 & 0 & 0 & 0 & 0 & 0 & 0 & 0 & 0 & 0 & 0\end{array}$ K51 $00 \begin{array}{lllllllllllllllllllllllllllll} & 0 & 0 & 0 & 0 & 0 & 0 & 0 & 0 & 0.2 & 0 & 0.4 & 0.2 & 0 & 0.2 & 1.2 & 0.2 & 0.2 & 0.2 & 0 & 0 & 0.2 & 0 & 0 & 0 & 0 & 0 & 0 & 0\end{array}$

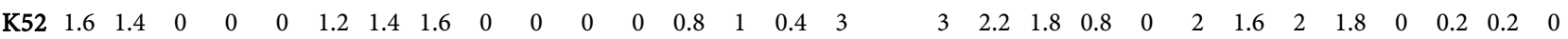
$\begin{array}{llllllllllllllllllllllllllllllll}\mathrm{K} 53 & 3.2 & 3 & 0 & 1.4 & 0 & 3.2 & 2.8 & 3.2 & 0 & 0 & 0 & 0 & 0 & 0 & 0 & 0.2 & 0.6 & & 0 & 0 & 0 & 0.2 & 0.2 & 0 & 0 & 0 & 0 & 0 & 0 & 0\end{array}$

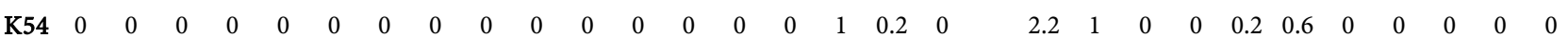

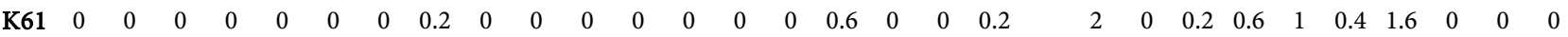

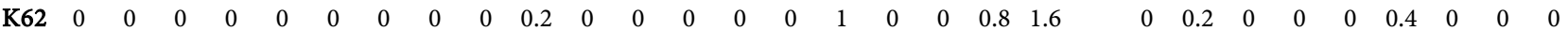

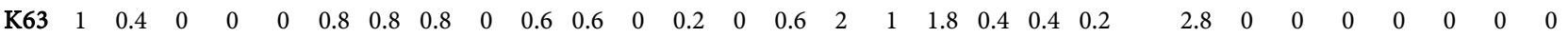

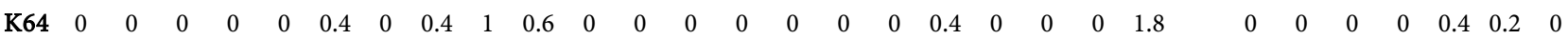
$\begin{array}{llllllllllllllllllllllllllllllll}\mathrm{K} 71 & 0 & 0 & 0.2 & 0 & 0 & 0 & 0 & 0 & 0 & 0 & 0 & 0 & 0 & 0 & 0 & 0 & 0 & 0 & 0 & 0 & 0 & 0 & 0 & & 2.6 & 1 & 1 & 0 & 0 & 0\end{array}$ $\begin{array}{lllllllllllllllllllllllllllllll}\text { K72 } & 0 & 0 & 0 & 0 & 0 & 0 & 0 & 0 & 0 & 0 & 0 & 0 & 0 & 0 & 0 & 0 & 0 & 0 & 0 & 0.2 & 0 & 0 & 0 & 1.8 & & 2 & 1.2 & 0 & 0 & 0\end{array}$ K73 $10 \begin{array}{llllllllllllllllllllllllllllll} & 0 & 0 & 0 & 0 & 0 & 0 & 0 & 0 & 0 & 0 & 0 & 0 & 0 & 0 & 0.2 & 0.2 & 0 & 0 & 0 & 0 & 0 & 0 & 1.8 & 2.8 & & 1.6 & 0 & 0 & 0\end{array}$

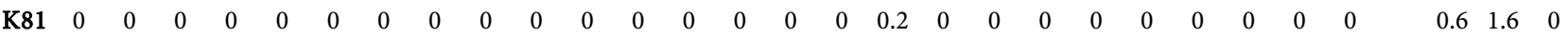
$\begin{array}{lllllllllllllllllllllllllllllll}\mathrm{K} 82 & 0 & 0 & 0 & 0 & 0 & 0 & 0 & 0 & 0 & 0 & 0 & 0 & 0 & 0 & 0 & 0 & 1.2 & 0 & 0 & 0 & 0 & 0 & 1.4 & 0 & 0 & 0 & 2.6 & 1.2 & 1\end{array}$

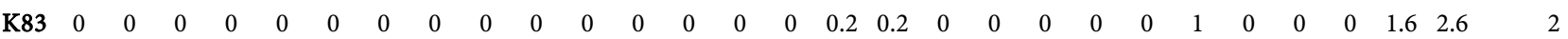

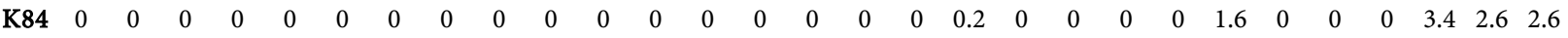

